\title{
O MODELO DE ORGANIZAÇÕES SOCIAIS INSERIDO NO HISTÓRICO DE REFORMAS ADMINISTRATIVAS NO BRASIL
}

\author{
Andrea Cabello* \\ Natália Vieira**
}

\begin{abstract}
Resumo: O artigo discute de forma histórica as principais reformas administrativas pelas quais o Brasil passou ao longo do século XX de modo a contextualizar a criação do modelo de Organizações Sociais (OSs) com foco em seu papel como mecanismo institucional de reestruturação do papel do Estado. São analisados a criação do DASP, a reforma de 1967 e a reforma de 1990, na qual foi criado o modelo OS, como resposta a um problema de crise fiscal e gerencial do Estado brasileiro. Discute-se seu uso no setor de saúde e de ciência e tecnologia e suas vantagens frente a restrições fiscais impostas por leis como a Lei de Responsabilidade Fiscal e questiona-se a falta de análises mais profundas sobre o uso do modelo na literatura e por órgãos de controle.
\end{abstract}

Palavras-Chave: Organizações Sociais, Reforma Administrativa, Administração Pública Brasileira.

\begin{abstract}
The article historically discusses the main administrative reforms that Brazil went through during the 20th century in order to contextualize the creation of the OS model with a focus on its role as an institutional mechanism for restructuring the role of the State. The creation of DASP, the 1967 reform and the 1990 reform, in which the OS model was created, are analyzed in response to a problem of fiscal and managerial crisis in the Brazilian State. Its use in the health and the science and technology sector and its advantages over tax restrictions imposed by laws such as the Fiscal Responsibility Law are discussed and the lack of deeper analysis on the use of the model in the literature and by control.
\end{abstract}

\footnotetext{
* Doutora em Economia, UnB - Departamento de Economia - UnB.

${ }^{* *}$ Doutora em Economia, UnB - Ministério de Comunicações .
} 
Keywords: Social Organizations, Administrative Reform, Brazilian Public Administration.

Resumen: El artículo analiza históricamente las principales reformas administrativas que sufrió Brasil a lo largo del siglo XX para contextualizar la creación del modelo de Organizaciones Sociales (OE), enfocándose en su rol como mecanismo institucional de reestructuración del rol del Estado. Se analiza la creación del DASP, la reforma de 1967 y la reforma de 1990, en la que se creó el modelo OS, como respuesta a un problema de crisis fiscal y gerencial en el Estado brasileño. Se discute su uso en el sector salud y el sector ciencia y tecnología y sus ventajas frente a las restricciones fiscales impuestas por leyes como la Ley de Responsabilidad Fiscal, y se cuestiona la falta de un análisis más profundo sobre el uso del modelo en la literatura y por las agencias de salud. control.

Palabras clave: Organizaciones sociales, Reforma administrativa, Administración pública brasileña.

\section{Introdução}

Atualmente, tem-se discutido no Brasil o papel do Estado e uma nova reforma administrativa. A última importante reforma ocorreu na década de 1990 e criou importantes inovações institucionais que modificaram o relacionamento do Estado com o setor privado na provisão de diversos serviços à sociedade.

Uma dessas inovações foi o modelo de Organizações Sociais (OSs). Esse modelo foi amplamente adotado no setor de saúde, principalmente no âmbito de estados e municípios, devido a sua flexibilidade orçamentária e contratual frente a opções inteiramente públicas. Na esfera federal, seu uso foi mais restrito e utilizado principalmente pelos Ministérios de Ciência, Tecnologia e Inovações (MCTI) e Ministério da Educação (MEC).

O artigo se propõe a discutir, de forma histórica, as principais reformas administrativas pelas quais o Brasil passou ao longo do século XX de modo a contextualizar a criação do modelo de OSs como mais um mecanismo institucional que reestrutura o papel do Estado. Nosso objetivo 
CABELLO, A.; VIEIRA, N. O modelo de organizações sociais inserido no histórico...

é contextualizar a criação do modelo de OSs no âmbito das reformas administrativas Nossa pergunta de pesquisa é, portanto: Como se situa historicamente o modelo de organizações sociais no âmbito das reformas administrativas no Brasil?

Defendemos que é importante analisar as OSs como um mecanismo institucional que reestrutura o papel do Estado, dado que seu uso tem sido proposto em diversos momentos nas últimas décadas como soluções de gestão a questões complexas.

O artigo está dividido em quatro seções além dessa introdução. A primeira discute brevemente as reformas administrativas da década de 1930 e da década de 1960, marcos institucionais para o Estado Brasileiro. A segunda seção discorre sobre a reforma administrativa da década de 1990, enquanto a terceira aborda a criação do modelo OSs no âmbito dessa reforma e a quarta seção traz nossos comentários finais.

\section{As primeiras Reformas Administrativas Públicas}

A estruturação da administração pública brasileira iniciou-se, de fato, a partir da Era Vargas, em que, para a construção de um Estado nacional forte, se fazia necessário que houvesse um corpo burocrático próprio, distante dos projetos individuais e relacionados às elites locais. Uma série de autores como Raymundo Faoro (2012), José Murilo de Carvalho (2003), Joaquim Nabuco (2019), Sérgio Buarque de Holanda (2015) indicavam o caráter clientelista e patrimonialista das relações público-privado no Brasil desde o Império.

Bresser-Pereira (2001) aponta que o fim do Império gerou a descentralização política para as oligarquias locais, elites essas que acabaram por alimentar o caráter patrimonialista do Estado. Era, inclusive, uma forma de emprego possível para a classe média que se formava nos centros urbanos e não conseguia se posicionar em uma sociedade ainda marcada pelo seu caráter rural. Um levantamento realizado pelo IPEA (2010) mostra que a quantidade de servidores públicos, civis e militares, na Primeira República, era ínfimo, representando $0,6 \%$ da população. Assim, em geral, o serviço público era ocupado por pessoas da elite, que se sentiam atraídas "pelas altas remunerações e pelo prestígio que o cargo 
proporcionava" (IPEA, 2010, p. 337), ligadas às práticas clientelistas e patrimonialistas que alimentavam esse 'privilégio'. Siegel (1966) também reforça o caráter elitista da contratação.

Eram justamente as carreiras militares, em especial o exército, uma das alternativas possiveis de posicionamento e para onde várias pessoas dessa nova classe média conseguiam se posicionar. Dessa forma, os militares do exército também se tornam um ponto de convulsão social durante a Primeira República e, a partir da década de 1930, ajudam na composição de uma elite burocrática, compondo a aliança de poder que se forma no governo varguista (FAUSTO, 1970).

O fortalecimento de um corpo burocrático era imprescindivel para sucesso do projeto nacional desenvolvimentista, caracterizado por ações conscientes do Estado no processo econômico a fim de promover o desenvolvimento nacional, em especial por meio da industrialização. Koury e Barbosa (2012) ressaltam o papel da estrutura institucional formada para o nacional desenvolvimentismo, assentado em um acordo ideológico de classes. Nesse sentido, o próprio Bresser Pereira (2001) ressalta a importância das duas novas classes sociais que surgem no período: a burguesia industrial e a classe média tecnoburocrática, essa última em especial oposição ao clientelismo e patrimonialismo, uma vez que tentava enfraquecer o poderio local de indicações políticas para cargos públicos.

Sola (1998, pp. 46-47) também reforça a importância que essa burocracia tecnocrática adquire dentro do Estado no aspecto econômico, já que se tornam "outro locus produtor de ideologia com força gravitacional comparável à irradiada a partir do Estado através desses através desses atores políticos.". No entanto, para melhor compreensão dessas construções, serão apresentadas as diferentes reformas que o setor público passou.

A criação do Conselho Federal do Serviço Público em 1936 foi o primeiro passo para a criação de uma administração pública. Na realidade, só com a sua transformação em Departamento Administrativo do Serviço Público (DASP), em 1938, é que houve a criação de um órgão que tinha o objetivo de "organizar e racionalizar o serviço público no país" (CPDOC, 2017). Wahrlich (1984) enfatiza que não havia um plano formal de reforma administrativa e tampouco teria sido adotado uma teoria administrativa que 
embasasse as medidas executadas. Isso implica que as medidas ocorreram, em sua maior parte, na estrutura da organização governamental.

O decreto-Lei $\mathrm{n}^{\circ} 579$ de 30 de julho de 1938 estabeleceu que o DASP teria a função de organização da administração pública, em especial, com a seleção de pessoal baseada no mérito $^{1}$, por meio de concursos públicos, a fim de dificultar as práticas patrimonialistas locais de indicação política, e a modernização administrativa, com o estabelecimento de uma burocracia racional-legal, nos moldes weberianos. Buscou-se a organização, centralização das decisões e o estabelecimento de métodos e de processos, com o objetivo de estabelecer o controle das atividades administrativas públicas.

Complementarmente, Leite (2019) indica que a criação do DASP foi um movimento inicial que facilitou a formação de outras estruturas administrativas. Loureiro (2009), inclusive, indica que o DASP se tornou uma espécie de "superministério". Isso foi fundamental para que o Estado conseguisse intervir na economia. Nunes (1997) demonstra que essa intervenção ocorre de 3 maneiras, com a criação de agências regulatórias e adoção de políticas regulatórias; com a criação de institutos e agências estatais para a 'defesa econômica' de determinados produtos e indústrias; e com a criação de empresas estatais e autarquias.

Começou a se formar uma elite tecnocrática que tentou se afastar da influência de grupos partidários. Essa elite se tornou um grupo ideológico que exercia forte influência nesse Estado e competia com setores mais tradicionais, que ainda usavam as brechas legais para nomeações políticas, e mantinham as práticas clientelistas e patrimonialista no seio estatal. Para tanto, seus membros usavam a burocracia, a gestão baseada nos procedimentos, a seu favor, contra o clientelismo desses grupos políticos que tentavam influir no Estado.

Wahrlich (1984) considera que essa reforma inicial teve como resultados a melhoria da qualidade dos funcionários públicos e a institucionalização da função orçamentária, associada ao planejamento. Entretanto, sua ênfase foi no controle e com forte teor político e coercitivo.

\footnotetext{
${ }^{1}$ Baseada na Reforma Inglesa de moralização do serviço público via sistema de mérito ocorrida entre 1850 e 1870 (IPEA, 2010).
} 
Até por isso, Siegel (1966) sugere que o sistema até então em curso foi visto com desconfiança assim que ocorreu a deposição de Getúlio Vargas e o fim do Estado Novo. O então presidente Linhares restringiu os poderes de coordenação, controle e de auditoria do DASP. No governo de Dutra, o DASP volta ter uma certa centralidade, principalmente pela dificuldade de articulação do presidente eleito e o Congresso. Observa-se, dessa forma, que o DASP precisou ir se adaptando as nuances políticas do período como estratégia para própria sobrevivência institucional, contudo não se deve perder de vista sua influência sobre a burocracia e o Estado.

Nos anos 1960, uma crise política que já se pendurava levou à ruptura institucional por meio de golpe militar e inicia-se o processo de reforma estrutural. Dias (1968) também aponta como o processo de reforma foi demandado a partir de tentativas e tramitações anteriores. A fim de reestruturar esse Estado, em busca de melhor eficiência ${ }^{2}$, tornou inevitável uma reforma administrativa, com o objetivo de dinamizar o Estado em sua recuperação econômica.

A reforma de 1967 consistia na tentativa de desburocratização do Estado, por meio do Decreto-Lei n ${ }^{\circ}$ 200/67. Segundo BresserPereira (1996), o Decreto Lei $n^{\circ}$ 200/67 se caracteriza por uma "Reforma Desenvolvimentista”, com características básicas, um precursor, do modelo gerencial que virá nos anos 1990. Mais ainda, ele tenta superar o excesso de procedimentos trazidos pela reforma burocrática dos anos 1930 e que trazia lentidão à administração pública, demasiadamente focada nos processos.

A ideia principal da reforma era, portanto, a modernização da administração pública, introduzindo os princípios gerenciais privados, com o objetivo de garantir maior agilidade e flexibilidade, em uma tentativa de se desprender das amarras burocráticas excessivas. O próprio Decreto-Lei 200/67 traz como princípios fundamentais o planejamento, a coordenação, a descentralização, a delegação de competência e o controle. Buscou promover a "relativa autonomia e modus operandi de pessoa jurídica de direito privado" das estatais (IPEA, 2010). Em um movimento de descentralização visando simplificar a gestão de pessoas (contratação e remuneração) e a gestão de materiais, foram dadas prerrogativas que

\footnotetext{
${ }^{2}$ A "eficiência da empresa privada", segundo Castello Branco em mensagem presidencial de 1965 (DIAS, 1968).
} 
CABELLO, A.; VIEIRA, N. O modelo de organizações sociais inserido no histórico...

garantiram uma maior liberdade econômica à administração indireta, o que passou a se diferenciar substancialmente da administração direta (central), que continuou presa às rotinas e à burocracia rígida. Para Wahrlich (1984), foi por meio dela que o Estado se expandiu, principalmente por meio de órgãos mais independentes, como empresas estatais, fundações e autarquias em um sistema de agência central com controle sobre os entes.

As principais críticas de Bresser Pereira (1996) à reforma administrativa do Decreto-Lei $n^{\circ} 200 / 67$ foram a possibilidade de contratação de empregados sem concurso público, o que fortaleceu as práticas patrimonialistas e fisiológicas; e a diminuição de formação (e contratação) de administradores públicos de alto nível na administração direta (central) e, consequentemente, do núcleo estratégico do Estado. O estudo do IPEA (2010) indica que a forma encontrada para contratação de pessoal altamente qualificado passou a ser via estatais e congêneres, formando-se "bolsões de eficiência" com conhecimento especializado e maior capacidade técnica, enquanto a administração direta, que deveria ser responsável pela formulação das politicas públicas, torna-se obsoleta e ineficiente pelo excesso de burocracia e procedimentos. Esse conjunto gerou uma tensão e disputa entre administração direta e indireta, com aquela saindo perdedora devido à insuficiência de capacidade para conseguir funcionar como esse núcleo estratégico que o Estado necessitava.

Na década de 1980, em um cenário de crise econômica e política, com uma gama de pessoas da classe média desempregadas, a forma de contratação da administração indireta também se tornou um ponto de estresse social, uma vez que o acesso aos cargos públicos se torna restrito e os que havia na administração indireta muitas vezes eram preenchidos com critérios clientelistas/patrimonialistas. Diante disso, a necessidade de reforma administrativa, em busca de relações mais eficientes e com custos menores, tornou-se como um ponto de pressão social. Conforme indica Marcelino (1985), o governo Sarney tentou realizar uma ampla Reforma Administrativa, com a criação de uma Comissão Geral de Reforma da Administração Pública Federal, que tinha como norte de atuação um processo de reorganização da administração pública, descentralização das atividades para Estados e Municípios, aperfeiçoamento dos seus quadros técnicos, além de contar com uma proposta de desestatização e privatização das atividades, bem como o uso da estrutura pública de forma mais racional, por meio de estruturas mais flexíveis e automatizadas. 
Todavia, conforme indica Costa (2008), a centralidade que a questão econômica tomou no governo Sarney contribuiu para que não se conseguisse que fossem implementadas as medidas da reforma preconizada pelo Comissão, mais ainda, o autor aponta que embora a Constituição Federal de 1988 tenha sido um avanço na democratização do Estado, configurando uma espécie de reforma do Estado, a Carta Magna também significou um retrocesso em termos de gerenciais. Nesse sentido, Bresser Pereira (1996) aponta que a alta burocracia se aproveitou da janela de oportunidade e, durante as discussões da Constituição, acabou se permitindo que "uma série de privilégios fossem consolidados e criados" para os servidores públicos, atendendo a interesses corporativistas. Mais ainda, foi promovido um "retrocesso burocrático" ao se enrijecer a burocracia de forma extrema.

De fato, novas reformas na administração pública só serão engendradas na década de 1990, quando novamente o Estado brasileiro repensa o seu tamanho, formas de diminuição de seus custos e incentivos à atuação privada em áreas não estratégicas, principalmente baseado nas experiências internacionais que buscavam uma atuação mais eficiente do Estado.

Esse não foi um fenômeno apenas brasileiro. Nos diversos países, as reformas desse tipo adquirem diferentes configurações de acordo com especificidades nacionais. No entanto, é na Inglaterra que ocorreu o modelo de reforma administrativa mais bem-sucedida do ponto de vista de redução de custos e melhoria do sistema, tornando-se modelo para outros países ao longo das últimas décadas, principalmente no que se refere a uma mudança de perspectiva de papel do Estado como único ou principal financiador do desenvolvimento econômico dos países.

Abrucio (2006) sugeriu que a crise no modelo burocrático ocorreu pela crise econômica mundial dos anos 1970 e 1980, com forte caráter fiscal que, segundo o autor, coloca "em xeque o consenso social que sustentara o Welfare State” (p. 176). Rezende (2002) chama a atenção para a importância de políticas de ajuste fiscal na motivação de reformas administrativas, inclusive.

Em um primeiro momento, as ações do governo Thatcher se voltaram para a necessidade de redução de seus custos e a melhoria de 
CABELLO, A.; VIEIRA, N. O modelo de organizações sociais inserido no histórico...

sua eficiência ${ }^{3}$. Já na metade dos anos 1980, novas demandas foram incorporadas, principalmente visando a qualidade, na medida que a crítica era que o modelo buscava a eficiência, e não a efetividade das ações. Posto isto, a reformulação se centrou em três pontos: uma descentralização administrativa a fim de facilitar a proximidade do 'consumidor' com o serviço prestado; a ideia de competição entre os serviços públicos; e, em especial, o estabelecimento de um novo modelo contratual com a finalidade de melhor controle e avaliação. Somente na fase posterior, já no começo dos anos 1990, o próprio conceito de cidadão passou a ser considerado como variável chave. Como boa parte dos conceitos do gerencialismo advém da iniciativa privada, a relação do serviço público com sua população era considerada uma relação entre consumidor e prestador de serviços. O fortalecimento dos regimes democráticos, as novas noções de accountability, transparência e equidade levaram a uma revisão do próprio modelo e na relação com o cidadão. Secchi (2009) alerta para a retórica e politicas simbólicas, sem resultados efetivos para cidadãos nesse debate.

Indubitavelmente, os Quangos(quasinon-governmentalorganizations), ou “organizações quase-não-governamentais", no Reino Unido foram inspiração para um dos pontos da reforma administrativa que ocorreu na década de 1990 no Brasil. Conforme explica Bresser Pereira (2000), os serviços não exclusivos do Estado não necessariamente precisariam ser promovidos pelo Estado, ao mesmo tempo em que o seu fornecimento só pela iniciativa privada poderia gerar externalidades negativas, além de ferir direitos humanos básicos, como acesso à saúde ou à educação. Assim sendo, um formato híbrido que combinaria entidades privadas, porém com finalidade pública não-estatal, ou seja, que não tivesse fins lucrativos, seria uma possibilidade no fornecimento dos serviços públicos. O Reino Unido passou a gestão de universidades e hospitais para os Quangos, o que foi considerado um ganho de eficiência na gestão dos recursos.

O formato dos quangos trouxe uma maior autonomia administrativa, sem o excesso de controle da administração direta, a possibilidade de

\footnotetext{
${ }^{3}$ Conforme demonstra Alcoforado (2012), o New Public Management foi uma iniciativa que veio dos próprios altos funcionários ingleses e consultores e que serviu como ponto de partida para um acordo do governo conservador de Thatcher e dos líderes dessa burocracia pública para uma reforma gerencial do setor público que, no fim, significou que outras reformas pensadas, de cunho mais liberal, como privatizações, fim do salário mínimo e redução dos programas sociais não fossem levadas adiante e a reforma do aparelho do Estado tenha se tornado a principal agenda do governo conservador inglês.
} 
contratação de pessoal, com atividades que poderiam ser exercidas por pessoas que não faziam parte do quadro de servidores públicos, porém com essas instituições privadas, sem fins lucrativos, fazendo parte do orçamento público. É importante ressaltar que a leitura de Bresser Pereira é que isso não significou a privatização das atividades, mas o repasse do "controle do Estado para o controle público” (BRESSER-PEREIRA, 2000, p. 22). É dentro dessa lógica que surge a ideia das Organizações Sociais no Brasil.

\section{A Reforma Administrativa dos anos 1990 no Brasil}

O processo de reforma tomou força ainda no Governo Collor, mas foi somente no governo Fernando Henrique Cardoso (FHC) que ela tomou formato definitivo, seguindo a tendência internacional de reforma de administrações públicas, baseando-se principalmente na ideia de um setor público mais eficiente e com maior controle de seus custos e de seu tamanho (SOUZA e CARVALHO, 1999). O então Ministro Bresser Pereira é quem encabeçou a bandeira da necessidade de uma reforma administrativa, inclusive estabelecendo um nexo de importância dessa reforma para o sucesso da reforma fiscal. Gaetani (2003) descreve o histórico de movimentação política da reforma em perspectiva histórica.

O Plano Diretor de Reforma do Aparelho do Estado (PDRAE) foi apresentado ainda em 1995 e trouxe uma série de conceitos-chave para o entendimento da reforma gerencial que estava sendo proposta pelo governo federal naquele momento. Pode-se destacar a ideia de profissionalização dos serviços, de reorganização da máquina estatal, da descentralização, da busca por eficiência e de controle por resultados (Brasil, 1995). Para tanto, foram estabelecidas as principais características necessárias na redefinição do papel do Estado que reduziria seu papel de executor e prestador de serviços diretos e teria funções mais regulatórias e provedoras.

Para a reforma, uma das primeiras definições que foram realizadas foi a separação de quais atividades deveriam ser executadas diretamente pelo Estado ou não. Dessa forma, o Plano Diretor trouxe a distinção entre quatro setores do Estado (Brasil, 1995):

a) Núcleo Estratégico - sentido lato do termo governo. Espaço em que as leis, o planejamento, a formulação das políticas públicas e as decisões estratégicas são definidas. É formada pelo próprio poder executivo 
CABELLO, A.; VIEIRA, N. O modelo de organizações sociais inserido no histórico...

(detentores de posições estratégicas como Presidente da República, aos ministros e aos seus auxiliares e assessores diretos), legislativo, judiciário e Ministério Público.

b) Atividades Exclusivas - são aquelas atividades que só podem ser realizadas pelo próprio Estado, como a fiscalização, a regulação, o fomento. Em geral, observa-se nesse espectro o poder de polícia do Estado, a capacidade de cobrança de impostos, o controle do meio ambiente.

c) Serviços não-exclusivos - são serviços em que o Estado pode atuar simultaneamente com entidades privadas. Essa atuação em concomitância ocorre por serem atividades de interesse público, ou seja, o fomento desses serviços para o Estado permite garantias constitucionais de direitos humanos fundamentais, bem como possuem externalidades positivas para a sociedade. O setor privado, por outro lado, pode fornecer esses serviços tanto visando o lucro (porém, nesse caso, sem subsídio estatal), quanto atuando em parceria com o Estado, desde que sem a finalidade lucrativa, seguindo os princípios gerenciais da administração, como são nos novos modelos de gestão pública. Inaugura-se a concepção de “propriedade pública não-estatal". Em geral, são serviços como hospitais, universidades, escolas, institutos de pesquisa, preservação do meio ambiente e da cultura. O PDRAE estabelece, inclusive, que a propriedade ideal é a pública não-estatal e permite um melhor controle social.

d) Produção de bens e serviços para o mercado - áreas em que o Estado atua, mas que poderiam ser exclusivamente fornecidas pelo setor privado. As atividades desse grupo têm a finalidade lucrativa e que, portanto, poderiam ser objetos de privatização, como o setor de infraestrutura.

De acordo com o PDRAE, no núcleo estratégico, o Estado deveria preocupar-se mais com a efetividade de suas ações do que com a eficiência. Nos demais campos, a preocupação deveria ser com a eficiência. Além disso, a reforma ainda previa, no plano de melhoria da governança, a transformação de autarquias e fundações em agências autônomas ${ }^{4}$, além

\footnotetext{
${ }^{4}$ As agências autônomas se subdividem em: a) agências reguladoras, tem o objetivo de intervir em mercados específicos, regulando a relação entre oferta e demanda. Exemplos: Agência Nacional de Telecomunicações (ANATEL); Agência Nacional de Petróleo (ANP), Agência Nacional de Saúde Suplementar (ANS); b) agências executivas, devem ser responsáveis pela implementação de políticas públicas (no caso, as agências executivas não eram responsáveis pela implementação ou regulação, somente pela implementação). Exemplo: Instituto Nacional de Metrologia, Normatização e Qualidade Industrial (Inmetro) (Souto, 1999).
} 
da publicização dos serviços não-exclusivos por meio das OSs.

É interessante observar que a divisão proposta se inseria dentro de uma discussão maior sobre qual deveria ser o papel do Estado, qual deveria ser o seu escopo de atuação e o que deveria ser provido pela iniciativa privada. Então, claramente, há ações que foram definidas como um núcleo estratégico do Estado e comportariam uma atuação estatal delimitada pelo papel de regulação, da própria governança e formulador de políticas públicas. No entanto, o papel executório não seria, em geral, de responsabilidade desse Estado. Ou ele seria dividido com o a iniciativa privada, no caso de serviços não-exclusivos, ou eles deveriam ser realizados pela iniciativa privada, seja por uma suposta capacidade de ser mais eficiente do que o serviço público, seja por uma própria reinvindicação do setor privado de retirada do Estado para que ele pudesse atuar de forma mais livre, sem ter como concorrente o próprio Estado.

\section{A Construção do Modelo de Organizações Sociais no Brasil}

OSs são uma forma de parceria entre o ente público e pessoas jurídicas de direito privado, sem fins lucrativos, "cujas atividades sejam dirigidas ao ensino, à pesquisa científica, ao desenvolvimento tecnológico, à proteção e preservação do meio ambiente, à cultura e à saúde" (BRASIL, 1998). É considerado um movimento em direção ao terceiro setor, em um processo de redefinição do Estado.

Para se tornar uma OS, é necessária sua qualificação. A qualificação é o ato, um título, em que o poder público outorga a uma entidade privada, sem fins lucrativos, para que ela tenha a capacidade de receber dotação orçamentária para a realização dos objetivos de sua atuação. Uma entidade qualificada pode assinar um contrato de gestão com o poder público. No contrato de gestão, são definidas, entre outros, as diretrizes, os objetivos estratégicos, o orçamento previsto daquela parceria e um quadro de indicadores e metas (QIM), que é o core do modelo. É o QIM que estabelece o que deverá ser entregue pela organização social, seguindo a ideia de controle por resultados, ou seja, é a busca pela eficiência pensada no PDRAE.

O Conselho de Administração é o principal espaço de gestão e poder deliberativo dentro das organizações sociais e possui atribuições especificas 
CABELLO, A.; VIEIRA, N. O modelo de organizações sociais inserido no histórico...

definidas na Lei $\mathrm{n}^{\circ} 9.637 / 98^{5}$. Sua composição, obrigatoriamente, deve contar com membros do poder público e da sociedade civil ${ }^{6}$, exatamente na ideia de parceria entre Estado e sociedade, além do exercício do controle social. Para colaborar com o processo de avaliação pelo Estado da parceria, no Governo Federal existem comissões de acompanhamento e avaliação do contrato de gestão, formadas pelo poder público e profissionais de notória capacidade naquela área, que emitem relatórios e atestam se o que foi pactuado no Quadro de Indicadores e Metas (QIM) foi atendido pela OS.

A despeito disso, o modelo encontrou várias resistências. Ainda em 1998, o Partido dos Trabalhadores (PT) e o Partido Democrático Trabalhista (PDT) entraram com a Ação Direta de Inconstitucionalidade (ADIN) $n^{\circ} 1.923$, em que questionavam a legalidade da Lei $n^{\circ}$ 9.637/98, a lei de criação do modelo OS, pois consideravam que o principal objetivo da norma era desresponsabilizar o Estado de suas obrigações, em especial, com uma forma de fuga aos processos de controle administrativo, o que poderia favorecer o desvio de dinheiro público e a contratação de pessoal por critérios não técnicos (no caso, sem o uso de concurso público). O julgamento pelo Supremo Tribunal Federal (STF) ocorreu apenas em 2015, quando a corte julgou o pedido parcialmente procedente, visto que a Lei não foi derrubada, mas ficou estabelecida a necessidade de que a seleção da entidade qualificada como OS deveria se dar de forma pública, objetiva e impessoal, assim como a própria forma de contração adotada pela OS, que também deve seguir esses princípios (LINS, 2018).

Indubitavelmente, o modelo OS encontrou no setor saúde o seu maior aliado. Em nível subnacionais, uma parte significativa dos estados regulamentaram localmente o modelo e começaram a aplicá-lo na gestão de hospitais e outros serviços de saúde. Krüger e Reis (2019) ressaltam que poucos planos estaduais plurianuais mencionam essa forma de gestão de forma explícita, apesar de seu uso difundido. Esse maior uso

\footnotetext{
${ }^{5}$ Até a sua conversão em Lei, houve três vezes a reedição da Medida Provisória de criação das organizações sociais, tendo pedido de urgência do poder executivo.

6 De acordo com o artigo $3^{\circ}$ da Lei $n^{\circ} 9.637 / 98$, o conselho de administração deve ter a seguinte composição "a) 20 a 40\% de membros natos representantes do Poder Público (...); b) 20 a 30\% de membros natos representantes de entidades da sociedade civil (...); c) até $10 \%$, no caso de associação civil, de membros eleitos dentre os membros ou os associados; d) 10 a 30\% de membros eleitos pelos demais integrantes do conselho, dentre pessoas de notória capacidade profissional e reconhecida idoneidade moral; e) até $10 \%$ de membros indicados ou eleitos (...).
} 
influenciou a pesquisa na área. A literatura recente, inclusive, é bastante escassa em relação à aplicação desse mecanismo fora da área de saúde e, consequentemente, em âmbito nacional. Apesar disso, há alguma discussão em relação ao seu uso na gestão de escolas estaduais, principalmente as militares (PINHEIRO e GUIMARÃES, 2018) e na gestão de universidades e seus fundos patrimoniais, devido à proposta do Governo Bolsonaro nesse sentido (SILVA E FARGONI, 2020; GIOLO, 2020; SOBRINHO, 2019).

A literatura indica que o aumento de seu uso ocorreu principalmente com o advento da Lei de Responsabilidade Fiscal (LRF), que estabeleceu limites para os gastos de pessoal na administração pública. É importante frisar que a LRF é um dos instrumentos de redução do tamanho do Estado, e funcionou como incentivo à adoção do modelo de organizações sociais. Dessa forma, modernizou-se os instrumentos e, ao mesmo tempo, foram impostos novos constrangimentos legais às unidades subnacionais para que esse instrumento fosse amplamente utilizado. Contrariamente ao esperado, não há uma redução efetiva da intervenção estatal, uma vez que o teto só se aplicaria ao gasto direto dos estados, mas não se aplicaria ao gasto por terceiros após repasse do recurso pelo poder público. Essa soma de fatores, na verdade, significou uma recaracterização do que é gasto fiscal. No caso específico das organizações sociais, houve essa introdução da relação privada que funcionou como uma forma de burlar a legislação.

Fato é que alguns estados, como São Paulo, Pernambuco, Bahia, Rio de janeiro, começaram a publicizar seus serviços de saúde, como forma de fugir do limite da LRF, já que as despesas dos contratos de gestão não estavam sujeitas aos limites impostos de gastos de pessoal, uma vez que entram na rubrica de custeio (PACHECO et al, 2016; IBANEZ et al, 2001; FERNANDES, 2018). Coelho e Greve (2016) sugerem que, embora partidos de esquerda tenham se posicionado contrários a modelo OS, principalmente pela contratação indireta de trabalhadores, na prática, eles acabaram adotando o modelo OS tão quanto as gestões de governos de direita e argumentaram que foram constrangidos devido à LRF.

Certamente, o modelo de contratação de pessoal para as organizações sociais, que deixava de ser via concurso público, e passava a ser por meio do regime celetista, com critérios de seleção mais próximos das entidades privadas, foi um dos pontos mais controversos do novo modelo, sendo acusado constantemente de 'terceirização' dos serviços. Nada obstante, os 
CABELLO, A.; VIEIRA, N. O modelo de organizações sociais inserido no histórico...

estudos sobre o tema ainda revelam que médicos e enfermeiros passaram a ter maiores salários dentro das organizações sociais em comparação ao serviço público e, por isso, seu grau de rotatividade é menor nas OSs. Na contramão, os demais trabalhadores de saúde recebem menores salários nas organizações sociais, portanto seu grau de rotatividade é maior nas OSs quando comparada aos servidores públicos de cargo similar (PILOTTO e JUNQUEIRA, 2017).

Druck (2016) demonstra que os próprios órgãos de controle, como o Tribunal de Contas da União (TCU), não conseguiram verificar em suas auditorias a economicidade e a produtividade do modelo OS. Esse é um ponto importante, pois existem três possibilidades para justificar tal fato: 1) Ou os indicadores que estão sendo pactuados não conseguem mensurar de forma adequada as vantagens do modelo; 2) Ou os órgãos de controle ainda não entenderam o modelo e estão apegados as formas tradicionais (burocráticas) de controle administrativo; 3) ou, realmente o modelo não conseguiu dar um salto de qualidade em termos de gestão pública.

De fato, Silva, Barbosa e Hortale (2016) realizaram uma série de entrevistas com gestores dos contratos de gestão e membros das OSs de saúde no Rio de janeiro e identificaram o medo dos técnicos atestarem os serviços, justamente pela carga de responsabilização que recai sobre o gestor do contrato nas fiscalizações pelos órgãos de controle. Por outro lado, foi identificado principalmente uma relação de subordinação das OSs com o Estado. Isso demonstra um desvirtuamento inicial do instrumento, que deveria servir como uma forma de parceria entre os agentes. Nota-se que a compreensão de que as OSs são entes que tem uma autonomia própria e não estão sujeitas as formas de controle por procedimentos, mas sim por resultados, ainda não está assimilada em parte significativa dos gestores.

Já o estudo de Schmidt (2011), no que diz respeito à comparação da diminuição das dividas públicas de estados que adotaram o modelo OS em relação aos que não adotaram, demonstra que no período de 1996 a 2005, houve uma diminuição das dividas públicas, porém não houve uma diminuição maior daqueles em relação a esses.

Como se pode observar, os principais estudos sobre OSs se concentram na área da saúde, principalmente por ser uma área com grupos de pesquisas consolidados e pelos dados de saúde serem de fácil 
acesso. Existem estudos pontuais sobre outras áreas publicizadas, como os contratos de gestão de cultura de São Paulo (NETTO, 2015). Em menor proporção, existem trabalhos publicados sobre as OSs do governo federal, no entanto, eles se concentram principalmente na questão legal do tema. Dessa forma, esse trabalho contribui com a literatura pelo foco em OSs da área de CT\&I de forma detalhada e seu papel sobre o financiamento do desenvolvimento tecnológico.

No que diz respeito às OSs do governo federal, a União já qualificou, desde a promulgação da lei, dez OSs, que ficaram sob a supervisão de diferentes órgãos da União, segundo sua área de atuação. O Quadro 1 traz essa relação:

\section{Quadro 1 - Relação de Organizações Sociais Qualificadas pelo Governo Federal}

\begin{tabular}{|c|c|c|}
\hline Organização Social & $\begin{array}{l}\text { Ministério } \\
\text { Supervisor }\end{array}$ & Situação Atual \\
\hline $\begin{array}{l}\text { Acerp - Associação de Comunicação } \\
\text { Educativa Roquette Pinto. }\end{array}$ & MEC & Sem contrato de Gestão \\
\hline $\begin{array}{l}\text { Bioamazônia - Associação Brasileira } \\
\text { para o Uso Sustentável da } \\
\text { Biodiversidade da Amazônia }\end{array}$ & MMA & Desqualificada em 2004 \\
\hline $\begin{array}{l}\text { Cebraspe - Centro Brasileiro de } \\
\text { Pesquisa em Avaliação e Seleção e de } \\
\text { Promoção de Eventos }\end{array}$ & MEC & Sem contrato de Gestão \\
\hline $\begin{array}{l}\text { CGEE - Centro de Gestão e Estudos } \\
\text { Estratégicos }\end{array}$ & MCTI & Contrato Vigente \\
\hline $\begin{array}{l}\text { CNPEM - Centro Nacional de } \\
\text { Pesquisa em Energias e Materiais }\end{array}$ & MCTI & Contrato Vigente \\
\hline $\begin{array}{l}\text { Embrapii - Empresa Brasileira de } \\
\text { Pesquisa e Inovação Industrial }\end{array}$ & MCTI & Contrato Vigente \\
\hline $\begin{array}{l}\text { IDSM - Instituto de Desenvolvimento } \\
\text { Sustentável Mamirauá }\end{array}$ & MCTI & Contrato Vigente \\
\hline $\begin{array}{l}\text { IMPA - Instituto de Matemática Pura } \\
\text { e Aplicada }\end{array}$ & MCTI & Contrato Vigente \\
\hline $\begin{array}{l}\text { ISD - Instituto de Ensino e Pesquisa } \\
\text { Alberto Santos Dumont }\end{array}$ & MEC & Contrato Vigente \\
\hline $\begin{array}{l}\text { RNP - Rede Nacional de Ensino e } \\
\text { Pesquisa }\end{array}$ & MCTI & Contrato Vigente \\
\hline
\end{tabular}

Fonte: Elaborado pela autora com base nos decretos federais de criação de organizações sociais

Nesse sentido, observa-se que, no âmbito federal, o uso do instrumento ainda é pouco disseminado, mas no último ano ele ganhou 
bastante visibilidade com a discussão, no âmbito do Ministério da Educação e a possibilidade de gestão de Universidades por meio de OSs, com o projeto Future-se. Não há experiência no país ainda que indique a pertinência de tal instrumento para essa área de atuação e mesmo nas áreas próximas, como Ciência e tecnologia, a literatura é escassa e alerta para a oscilação de recursos em tempos de ajuste fiscal (VIEIRA, 2020).

Sua grande vantagem parece ser a flexibilidade orçamentária e capacidade de contratação de pessoal com requisitos mais simples, mas isso tem lados negativos no sentido de que recursos podem também ser cortados de forma intempestiva caso a conjuntura macroeconômica exigir.

De toda sorte, o modelo OS tem sido abalizado no Governo Federal, tendo em vista que, nos últimos anos, têm ocorrido tentativas de criação de novas OSs, alguns exemplos foram: o Centro de Biotecnologia da Amazônia $(\mathrm{CBA})^{7}$; a Unidade de Escola Acadebio/ Flona de Ipanema ${ }^{8}$; e Instituto Nacional de Pesquisas Oceânicas e Hidroviárias (INPOH) ${ }^{9}$.

\section{Comentários Finais}

O artigo visou indicar que a criação do modelo de OSs não está dissociada do próprio contexto histórico de Reformas Administrativas no Brasil. As Reformas Administrativas estiveram relacionadas à modernização do aparato institucional do Estado dada as demandas históricas de um determinado período. Essas demandas se alteram, seja pela necessidade de criação de um aparato estatal que dê o suporte necessário para a estruturação de um Estado Nacional forte, seja, posteriormente, pela própria modernização desse Estado, rumo a um caráter mais gerencial na administração pública e de maior busca por eficiência. Graham (2014), no entanto, questiona que, apesar dessa busca recorrente ao longo das últimas décadas, não é claro se o objetivo de eficiência foi de fato alcançado.

\footnotetext{
${ }^{7} \mathrm{Em} \mathrm{2018}$, houve chamamento público para seleção de entidade, que ficaria sob a responsabilidade do Ministério do Desenvolvimento, Indústria e Comércio Exterior (MDIC), no entanto não houve a criação da OS.

${ }^{8}$ Em 2018, houve chamamento público para a seleção da entidade, que ficaria sob a responsabilidade do Instituto Chico Mendes de Conservação e Biodiversidade (ICMBio), no entanto não houve a criação da OS.

${ }^{9}$ Desde de 2013, há a previsão da criação da OS pelo MCTI, todavia ainda não houve chamamento público.
} 
As OSs se inserem nesse contexto, na medida em que foram uma resposta, durante as reformas da década de 1990, à demanda de um Estado menos burocrático, menos custoso e mais eficiente nas respostas à sociedade. O modelo OS se fortaleceu nos governos locais, principalmente na área de saúde. No governo federal, o modelo se propagou de forma mais discreta, em especial no Ministério da Ciência, Tecnologia e Inovações e no Ministério da Educação.

Elas tiveram um papel importante no gerenciamento de gastos fiscais, principalmente nos gastos de pessoal tendo em vista as restrições da LRF e as facilidades de contratação que o modelo colocava, dada a possibilidade de assinatura de contratos de gestão e um maior papel de instituições privadas na provisão de serviços. Dessa forma, configurouse como importante inovação de gestão no setor público brasileiro, cujas características e consequências ainda não foram completamente mapeadas pela literatura. Assim, como esforço de pesquisa futura, aponta-se a necessidade de estudo mais detalhado sobre a eficácia e eficiência da adoção de tais arranjos nos diferentes setores da gestão pública brasileira de modo a orientador formuladores de politicas públicas acerca das suas vantagens e limites. Por fim, a dificuldade de órgãos de controle de também fazer uma análise precisa do modelo pode ser amparada por esse tipo de pesquisa, uma vez que muitos indicadores apontados nos contratos de gestão atuais são incapazes de fornecer um retrato adequado do impacto do modelo na eficiência do modelo na administração pública brasileira.

$\mathrm{O}$ artigo contribui com a literatura, principalmente ao avaliar esses mecanismos em um escopo mais amplo, fora da área da saúde. Como mencionado, a literatura recente é bastante escassa em relação à aplicação desse mecanismo fora dessa área e do âmbito estadual. Recentemente, a proposta de uso na educação, levou a novas contribuições sobre seu uso na gestão de escolas estaduais (PINHEIRO e GUIMARÃES, 2018) e na gestão de universidades e seus fundos patrimoniais, devido à proposta do Governo Bolsonaro nesse sentido (SILVA E FARGONI, 2020; GIOLO, 2020; SOBRINHO, 2019). 


\section{Referências}

ABRUCIO, L. "Os avanços e os dilemas do modelo pós-burocrático: a reforma administrativa pública à luz da experiência internacional recente". In: BRESSER PEREIRA, L. SPINK, P. Reforma do Estado e Administração Pública Gerencial, Rio de Janeiro: Editora FGV, 7. ed., 2006.

ALCOFORADO, Flávio Carneiro Guedes. Obstáculos à Implementação da Reforma Gerencial: As Organizações Sociais. Tese de Doutorado. FGV, São Paulo, 2012

BRASIL. Decreto-Lei n ${ }^{\circ} 579$ de 30 de julho de 1938. Organiza o Departamento Administrativo do Serviço Público, reorganiza as Comissões de Eficiência dos Ministérios e dá outras providências. Rio de Janeiro, 1938.

BRASIL. Decreto-lei $n^{\circ} .200$, de 25 de fevereiro de 1967. Dispõe sobre a organização da Administração Federal, estabelece diretrizes para a Reforma Administrativa e dá outras providências. Diário Oficial da República Federativa do Brasil, Brasília, DF, 27 de fevereiro de 1967.

BRASIL. Presidência da República. Plano Diretor da Reforma do Aparelho do Estado. Brasília. 1995.

BRASIL. Lei ${ }^{\circ} 9.637$ de 15 de maio de 1998. Dispõe sobre a qualificação de entidades como organizações sociais, a criação do Programa Nacional de Publicização. Brasília, 1998.

BRESSER PEREIRA, L. Da Administração Pública Burocrática à Gerencial. Revista do Serviço Público. Brasília.1996.

BRESSER PEREIRA, L. A Reforma Gerencial do Estado de 1995. Revista de Administração Pública, vol. 34, no. 4, pp. 7-26, Jul./Ago. 2000

BRESSER PEREIRA, L. "Do Estado Patrimonial ao Estado Gerencial". In PINHEIRO, WILHEIM e SACHS (orgs.), Brasil: Um Século de Transformações. São Paulo: Cia. Das Letras, 2001.

CARVALHO, J. A Construção da Ordem: teatro de sombras. Editora Record, 2003. 
COELHO, V.; GREVE, J. "As Organizações Sociais de Saúde e o Desempenho do SUS: Um Estudo sobre a Atenção Básica em São Paulo”. Dados, Rio de Janeiro, v. 59, n. 3, pp. 867-901. 2016,

COSTA, F. L. da. "Brasil: 200 anos de Estado; 200 anos de Administração Pública, 200 anos de reformas.". Rev. Adm. Pública 42 (5) • Out 2008.

CPDOC. A Era Vargas: dos Anos 20 a 1945. Departamento Administrativo do Serviço Público (DASP). Centro de Pesquisa e Documentação de História Contemporânea do Brasil. FGV. 2017.

DIAS, J. A Reforma Administrativa de 1967, Cadernos de Administração Pública - 73, Fundação Getúlio Vargas, 1968.

DRUCK, G. "A Terceirização na Saúde Pública. Formas Diversas de Precarização do Trabalho". Trab. educ. saúde, Rio de Janeiro, v. 14, supl. 1, p. 15-43, Nov. 2016.

FAUSTO, B. A Revolução de 1930: historiografia e história. Editora Brasiliense, 1972.

FAORO, R. Os Donos do Poder: Formação do Pensamento Político Brasileiro, Biblioteca Azul: 4ª edição. 2012.

FERNANDES, L., SOARES, G., TURINO, F. BUSSINGER, E., SODRÉ, F. "Recursos Humanos em Hospitais Estaduais Gerenciados por Organizações Sociais de Saúde”. A Lógica do Privado. Trab. educ. saúde, v. 16, n. 3, p. 955-973, Dec. 2018.

GAETANI, F. "O recorrente apelo das reformas gerenciais: uma breve comparação", Revista do Serviço Público, 54, 4, out-dez, 2003.

GIOLO, J. O future-se sem futuro. Revista Direitos, Trabalho e Política Social, 6(10), 261-350, 2020.

GRAHAM, L. Civil Service Reform in Brazil: Principle Versus Practice, University of Texas Press, 2014.

HOLANDA, S. Raizes do Brasil, Companhia das Letras, 2015. 
IBANEZ, N. BITTAR, O, SÁ,E., YAMAMOTO, E., ALMEIDA, M, CASTRO, C. "Organizações sociais de saúde: o modelo do Estado de São Paulo". Ciênc. saúde coletiva, São Paulo, v. 6, n. 2, p. 391-404, 2001.

IPEA. Estado, Instituições e Democracia: República. Instituto de Pesquisa Econômica Aplicada (IPEA). Brasília: IPEA, 2010.

KOURY, A. e BARBOSA, A. "Rômulo Almeida e o Brasil desenvolvimentista (1946-1964): ensaio de reinterpretação". Economia e Sociedade. Vol. 21(SPE), pp. 1075-113, 2012.

KRÜGER, T. R.; REIS, C. Organizações sociais e a gestão dos serviços do SUS. Serviço Social \& Sociedade, 271-289, 2019.

LEITE, L. "História da Reforma Gerencial do Estado de 1995". Tese (doutorado CDAPG) - Fundação Getulio Vargas, Escola de Administração de Empresas de São Paulo. 2019

LINS, B. Organizações Sociais e contratos de Gestão. -2. ed. Rio de Janeiro: Lumen Juris, 2018.

LOUREIRO, M. "Economists in the Brazilian Government: from Developmentalist State to Neoliberal Policies". In: MONTECINOS, V.. MARKOFF, J. (orgs) Economists in the Americas, Edward Elgar, 2009.

MARCELINO, G. F. “A Reforma Administrativa na Nova República”. Revista Estudos. 1985.

NABUCO, J. O Abolicionismo, Câmara dos Deputados: Edições Câmara, 2019.

NETTO, J. "Gestão de políticas de cultura e qualidade da democracia: São Paulo, 10 anos de um modelo ainda em construção". Rev. Adm. Pública, Rio de Janeiro , v. 49, n. 4, p. 1011-1038, Aug. 2015.

NUNES, E.. A gramática politica do Brasil: clientelismo, corporativismo e insulamento burocrático. Rio de Janeiro: Garamond, 1997.

PACHECO, H.; GURGEL JÚNIOR, G.; SANTOS, F.; FERREIRA, S.; LEAL, 
E. "Organizações sociais como modelo de gestão da assistência à saúde em Pernambuco, Brasil: percepção de gestores”. Interface, v. 20, n. 58, p. 585595, Sept. 2016.

PILOTTO, B.; JUNQUEIRA, V. "Organizações Sociais do setor de saúde no estado de São Paulo: avanços e limites do controle externo". Serv. Soc. Soc., São Paulo, n. 130, p. 547-563, Dec. 2017.

PINHEIRO, V.; GUIMARÃES, G. A Educação na Sociedade da Mercadoria: a questão dos Colégios Militares e as Organizações Sociais em Goiás. Perspectivas em Diálogo: revista de educação e sociedade, 5(9), 253-268, 2018.

REZENDE, F. "Por que reformas administrativas falham?". Revista Brasileira de Ciências Sociais, ol.17 no.50 São Paulo Oct. 2002.

SCHMIDT, V. "Coerência programática e disciplina parlamentar: partidos políticos frente à proposta das organizações sociais". Rev. Sociol. Polit., v. 19, n. 40, p. 211-231, Oct. 2011.

SILVA, V.; BARBOSA, P.; HORTALE, V.. "Parcerias na saúde: as Organizações Sociais como limites e possibilidades na gerência da Estratégia Saúde da Família". Ciênc. saúde coletiva, v. 21, n. 5, p. 1365-1376, 2016.

SILVA, J. E FARGONI, E. Future-se: o ultimato na universidade estatal brasileira. Educação \& Sociedade, 41, 2020.

SECCHI, L. "Modelos organizacionais e reformas da administração pública", Rev. Adm. Pública, vol.43 no.2 Mar./Apr. 2009.

SIEGEL, G. "The Strategy of Public Administration Reform: The Case of Brazil", Public Administration Review, Mar., 1966, Vol. 26, No. 1, pp. 45-55, 1966.

SOBRINHO, Z. P. FUTURE-SE. Revista FIDES, 10(2), 50-68, 2019.

SOLA, L. Ideias Econômicas: Decisões Políticas. EDUSP; 1998.

SOUTO, M. "Agências reguladoras". Revista de Direito Administrativo, v. 
CABELLO, A.; VIEIRA, N. O modelo de organizações sociais inserido no histórico...

216, p. 125-162, abr. 1999.

SOUZA, C.; CARVALHO, I. "Reforma do Estado, descentralização e desigualdades", Lua Nova no.48 Dec. 1999.

VIEIRA, N. "20 anos de Publicização: Organizações Sociais em Ciência e Tecnologia". Tese de Doutorado. Doutorado em Economia. Universidade de Brasília, 2020.

WAHRLICH, B. "A Reforma Administrativa no Brasil: Experiência Anterior, Situação Atual e Perspectivas - Uma Apreciação Geral”, Revista de Administração Pública, 18, 1, p. 49-59, jan-mar, 1984. 